Proceedings of the

International Geometry Center

Vol. 9, no. 2 (2016) pp. 32-41

\title{
Топологія потоків Морса-Смейла 3 особливостями на межі двовимірного диска
}

\author{
М. В. Лосєва, О. О. Пришляк
}

\begin{abstract}
We analyze topological properties of Morse-Smale flows on twodimensional disk whose singularities lie on the boundary of the disk. A complete topological invariant for such flows is constructed. We also obtain a topological classification of these flows and propose a method of their enumeration.
\end{abstract}

Анотація. В роботі досліджуються топологічні властивості потоків Морса-Смейла на двовимірному диску, у яких особливості лежать на межі диска. Побудовано повний топологічний інваріант цих потоків. Отримана їх топологічна класифікація та запропоновано спосіб їх нумерації.

\section{ВСтУП}

На замкненому многовиді векторне поле завжди породжує потік. У випадку компактного многовиду з межею векторне поле буде породжувати потік тоді і тільки тоді, коли воно дотикається до межі в кожній її точці [1].

Нехай $H$ - компактний многовид з межею $\partial H$. Позначимо через $\mathfrak{X}(H, \partial H)$ простір векторних $C^{r}$ полів на $H$ дотичних до $\partial H$, оснащений звичайною $C^{r}$ топологією. В цьому просторі можна наступним чином визначити структурну стійкість: векторне поле $X \in \mathfrak{X}(H, \partial H) \in C^{r}$ структурно стійким якщо воно має $C^{r}$ окіл $\mathfrak{U}$, такий, що кожне поле $Y \in \mathfrak{U} \in$ топологічно еквівалентним до $X$, тобто існує гомеоморфізм $h$, що переводить орбіти $X$ в орбіти $Y$ та зберігає їх орієнтацію.

Для поля $X \in \mathfrak{X}^{\infty}(H, \partial H)$ позначимо через $\omega(X)$ множину його неблукаючих точок.

Ключові слова: топологічна класифікація, потоки, поверхня з межею

УДК 517.956 .4 
Нехай $H$ - замкнений многовид класу $C^{\infty}$ і $X^{r}(H), r \geq 1,-$ множина векторних $C^{r}$ полів з $C^{r}$ топологією. Тоді векторне поле $X \in X^{r}(H)$ називається полем Морса-Смейла якщо виконуються такі умови:

(1) $\omega(X)$ є простою, тобто вона має лише скінченну кількість орбіт, усі 3 яких гіперболічні;

$(2)$ якщо $\sigma_{i}, \sigma_{j} \in \omega(X)$ тоді нестійкий многовид $W^{U}\left(\sigma_{i}\right)$ трансверсальний до стійкого многовиду $W^{S}\left(\sigma_{j}\right)$.

Топологічній класифікації полів Морса-Смейла присвячено багато робіт, зокрема [2], [8], [6].

Множина векторних полів Морса-Смейла є відкритою і непорожньою множиною в $\mathfrak{X}^{r}(\widetilde{H}), r \geq 1$, а кожен $\dddot{1}$ елемент структурно стійкий [4], [5].

Поля, що знаходяться в загальному положенні до межі многовиду, (m-поля) досліджувались в роботах [9], [10], [11].

Полем Морса на многовиді з межею будемо називати векторне поле $X \in X^{r}(H)$, що задовольняє такі умови:

(1) $\omega(X)$ є скінченою, тобто має скінченне число точок, усі з яких є гіперболічними особливими точками;

$(2)$ якщо $\sigma_{i}, \sigma_{j} \in \omega(X)$ і в точці $x \in W^{U}\left(\sigma_{i}\right) \cap W^{S}\left(\sigma_{j}\right)$ стійкий та нестійкий многовиди перетинаються нетрансверсально, то $x \in \partial H$;

(3) поле дотичне до межі і його обмеження на межу є полем МорсаСмейла.

На замкнених поверхнях потоки Морса-Смейла утворюють скрізь щільну множину на множині всіх потоків. Серед потоків, у яких множина неблукаючих точок складається зі скінченого числа траєкторій, структурно стійкими є лише потоки Морса-Смейла. Аналогічні результати мають місце і для многовидів з межею. Зокрема, ці результати доведені в роботах [3], [7].

Мета даної роботи описати топологічну структуру потоків МорсаСмейла на двовимірному диску, у яких особливості лежать на межі диска.

\section{1. Прості ПОтоки}

Потік Морса-Смейла на двовимірному диску будемо називати простим, якщо у нього всі особливості лежать на межі.

Лема 1.1. Простий потік Морса-Смейла на двовимірному диску не містить замкнених траекторій. 
Доведення. Припустимо, що потік має замкнену траєкторія. Тоді вона обмежує область, що гомеоморфна двовимірному диску. Відобразимо цю область на верхню півсферу. При цьому потік на області буде індукувати потік на верхній півсфері. Застосувавши симетрію відносно горизонтальної площини побудуємо потік на нижній півсфері, що продовжує потік з верхньої півсфери. Тоді отримає потік на двовимірній сфері без нерухомих точок, що неможливо, бо за теоремою ПуанкареХопфа сума індексів нерухомих точок потоку на сфері повинна дорівнювати 2. Отримане протиріччя доводить лему.

Всі нерухомі точки потоку на 2-диску поділяються три типи: 1) витоки, 2) стоки, 3) сідла.

В подальшому, для сідлових особливих точок будемо використовувати такі назви:

1) $a$-сідло для особливої точки в яку входять дві траєкторії і з якої виходить одна (вона є стоком при обмеженні потоку на межу),

2) $b$-сідло для особливої точки з якої виходять дві траєкторії і в яку входить одна (вона є витоком при обмеженні потоку на межу) (Див. рис. 1.1.)
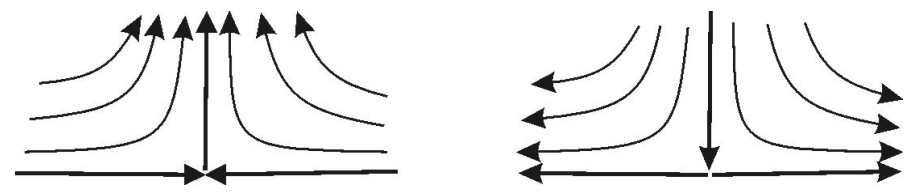

Рис. 1.1. $а$-сідло (зліва) та $b$-сідло (справа)

Лема 1.2. Для простого потоку Морса-Смейла на двовимірному диску з $s$ нерухомими точками число сідел l дорівнюе

$$
l=(s-2) / 2 .
$$

Доведення. Нехай простий потік має $k$ витоків, $m$ стоків та $l$ сідел $(s=k+l+m)$. Так само як і в лемі 1.1, подвоївши потік на сферу і застосувавши формулу Ейлера для ейлерової характеристики, маємо $k-l+m=2$. Звідки $s=k+l+m=2+2 l$, що і дає потрібну формулу.

\section{2. СЕПАРАТРИСНА ДІаГРАМА}

Сепаратрисою називається траєкторія, що входить або виходить із сідла та не лежить на межі диска. Сепаратрису також можна охарактеризувати як внутрішню траєкторію, для якої існує окіл $U$ такий, 
що для довільної точки $x$ сепаратриси і довільного околу $V$ цієї точки, існує точка $y \in V$, траєкторія якої не міститься в $U$.

Сепаратрисною діаграмою простої функції називається орієнтований граф, вершинами якого є нерухомі точки потоку, а ребрами - траєкторії межі та сепаратриси, причому орієнтація ребер відповідає напрямку руху за траєкторіями і на графі виділений цикл, що складається з траєкторій межі.

Дві сепаратрисні діаграми називаються еквівалентними, якщо між їх графами існує ізоморфізм, що зберігає орієнтації ребер та відображає виділений цикл у виділений цикл.

Ребра на виділеному циклі будемо називати граничними, а сепаратриси - внутрішніми. Отже, топологічна еквівалентність відображає граничні ребра на граничні ребра, а внутрішні - на внутрішні.

Лема 2.1. Сепаратрисна діаграма має такі властивості:

1) Для кожннӧ сепаратриси принаймні один з ї кінців є вершиною валентності 3 .

2) Число сепаратрис l та число вершин s пов'язані бормулою (1.1).

3) Кожнна сепаратриса розбиває виділений цикл на дві частини (кіниі сепаратриси належсть кожнній з чих частин) так, що

а) в кожній з частин непарне число вершин;

b) для будь-якої іншої сепаратриси обидва ї кіниі належать одній 3 двох частин.

4) Для кожної вершини, обидва іниидентні ребра з граничного ииклу мають по відношенню до иієї вершини однаковий напрямок, тобто обидва входять в неї або обидва виходять з неї.

5) Якщо якійсь з вершин іниидентні більше ніж одна сепаратриса, то всі иі сепаратриси мають по відношенню до вершини напрямок такий, як і іниидентні їй граничні ребра (ияя вершина є стоком або витоком).

Доведення. 1) Сідло є вершиною валентності 3 і одним з кінців сепаратриси.

2) Кожна сепаратриса містить рівно одне сідло як один із своїх кінців, і кожне сідло є кінцем сепаратриси. Тому сепаратрис і сідел однакове число, яке, згідно леми, обчислюється за формулою (1.1).

3) Якщо обмежити потік на межу (коло), то матимемо два типи нерухомих точок - витоки і стоки, які чергуються між собою. Нехай сепаратриса виходить із сідлової точки ( $a$-сідло). Тоді ця точка є стоком для обмеження потоку на межу. Інший кінець також є стоком. Тому в одній з частин разом із зазначеними двома точками буде на стоків буде на один більше ніж витоків (ми починаємо обходити нерухомі точки зі 
стоку, вони чергуються і закінчуємо стоком). Отже, всього нерухомих точок непарне число. Те, що для іншої сепаратриси обидва кінці лежать в одній частині рівносильне тому, що сепаратриси не перетинаються.

4) Ця властивість безпосередньо перевіряється для кожного з чотирьох типів нерухомих точок.

5) Якщо валентність вершини більша за 3, то ця точка не може бути сідлом, бо їх валентність дорівнює 3. Отже, вона є стоком або витоком. Лему доведено.

\section{3. ТОПОЛОГІЧНА ЕКВІВАЛЕНТНІСТЬ ПОТОКІВ}

Теорема 3.1 (Критерій топологічної еквівалентності). Два простих потоки на 2-диску будуть топологічно еквівалентними тоді та тільки тоді, коли їх сепаратрисні діаграми ізоморфні.

Доведення. Необхідність. Топологічна еквівалентність відображає особливі точки у особливі точки, сепаратриси - на сепаратриси, граничні траєкторії на - граничні траєкторії, а отже, породжує ізоморфізм сепаратрисних діаграм.

Достатність. Ізоморфізм сепаратрисних діаграм задає бієктивні відповідності між множинами особливих точок, множинами сепаратрис та множинами граничних траєкторій. Нехай $x, y$ - стандартні координати на 2-диску. Розглянемо на ньому стандартну ріманову метрику. Для кожного зовнішнього та внутрішнього ребра знайдемо середину у цій рімановій метриці. Для кожного з потоків розглянемо такі досить малі $\epsilon$-околи цих середин, які не перетинаються між собою, а також з іншими сепаратрисами та граничними траєкторіями. Якщо для першого потоку для одного з ребер $е$, його довжина менша ніж відповідна довжина у ребра другого потоку, то розтягнемо ребро $е$ в його середині p. Для цього розглянемо ріманову метрику

$$
d s^{2}=\left(1+h_{x}^{2}\right) d x^{2}+2 h_{x} h_{y} d x d y+\left(1+h_{y}^{2}\right) d y^{2},
$$

де

$$
h(x, y)=\left\{\begin{array}{r}
c e^{\frac{1}{x^{2}+y^{2}-\epsilon^{2}}}, x^{2}+y^{2}<\epsilon^{2} \\
0, x^{2}+y^{2} \geq \epsilon^{2}
\end{array}\right.
$$

При збільшенні константи с збільшується і довжина ребра $е$. Оскільки ми можемо так збільшувати довжину ребра до як завгодно великої величини і це збільшення неперервно залежить від $c$, то знайдеться таке значення $c$, при якому довжини відповідних ребер однакові. Пророблюючи цю процедуру з кожним ребром, ми отримаємо ріманові метрики, в яких довжини відповідних ребер однакові. Якщо $s_{1}$ - натуральний 
параметр на ребрі першого потоку, а $s_{2}$ - на відповідному ребрі другого потоку, відкладені від відповідних вершин, то рівність $s_{2}=s_{1}$ задає гомеоморфізм між відповідними ребрами.

Продовжимо отриманий гомеоморфізм в середину кожної з областей. Для цього в кожній області $U$ розглянемо вершину витік і таку систему координат $x, y$, в якій векторне поле $X=\{x, y\}$ є полем швидкостей потоку. Гомеоморфно відобразимо дугу $\left\{x, y \mid x^{2}+y^{2}=\epsilon^{2}\right\} \cap U$ першого потоку на відповідну дугу другого потоку. Цей гомеоморфізм задає відповідність між траєкторіями. Гомеоморфізм між відповідними траєкторіями будемо будувати за допомогою натуральних параметрів за формулою $s_{2}=k s_{1}$, де константа $k$ дорівнює відношенню довжин відповідних траєкторій. Оскільки кожна траєкторія з внутрішності області починається в якомусь витоку, то ці гомеморфізми задають відображення 2-диска, яке за побудовою є гомеоморфізмом, що відображає траєкторії на траєкторії, тобто є топологічною еквівалентністю. Теорему доведено.

Теорема 3.2 (Реалізація). Оріентований граф з виділеним ииклом $\epsilon$ сепаратрисною діаграмою деякої простої функиї, якщо він задовольняе властивостям 1)-5) з леми 2.1.

Доведення. 3 умови 3)-а) леми 2.1 випливає парність вершин графа. Зафіксуємо на межі 2-диску ці вершини у вершинах правильного многокутника. Умова 3)-а) рівносильна тому, що якщо побудувати сепаратриси як хорди в 2-диску, то вони не будуть перетинатися. Будемо розглядати області, на які сепаратриси (хорди) розбивають 2-диск, як криволінійні многокутники.

Покажемо, що в кожній такій області є єдина вершина витік і єдина вершина стік. 3 умови 3)-а) випливає, що для кожної сепаратриси один з ï кінців є сідлом, а інший - стоком або витоком. Зафіксуємо область і сепаратрису з ї межі. Нехай ця сепаратриса починається в $a$-сідлі (випадок $b$-сідла аналогічний, з заміною всіх напрямків руху на протележні). Тоді вона закінчується у стоці. Значить у області є стік на межі. Розглянемо траєкторію на межі області, що закінчується у цьому стоці. Початок цієї траєкторії є або витоком або b-сідлом. Отже, у першому випадку є виток на межі. У другому випадку витоком буде початок сепаратриси, що входить це $b$-сідло.

Те, що інших витоків і стоків на межі не існує, доводиться від супротивного. Наприклад, якщо існує 2 витоки, то розглянувши об'єднання траєкторій, що виходять з першого витоку, і об'єднання траєкторій, що виходять з другого витоку, отримаємо сепаратрису, яка лежить на перетині їх меж, а це суперечить визначенню області. Якщо $a(t)$ і $b(t)-$ 
шляхи, що починаються у витоку і закінчуються у стоці (об'єднання яких дає всю межу області), то траєкторії всередині області можна задати рівнянням $(1-s) a(t)+s b(t)$ для $s \in[0,1]$. Проробивши це для кожної області отримаємо шуканий потік на 2-диску.

\section{4. Код ПОтОку}

Задамо циклічну нумерацію вершин. В якості першої вершини виберемо одну з вершин з найбільшою валентністю (якщо всі вершини мають валентність 3 - то стік або витік).

Складемо список, що починається 3 1, а далі за зростанням йдуть номери сідел, що є кінцями сепаратрис, інцидентних вершині 1. Наприклад, $1-3-5$.

Далі, для вершини з найменшим номером, що не є сідлом, складемо аналогічний список, наприклад $8-6$.

Продовжимо цю процедуру для інших вершин і в результаті отримаємо, набір списків. Якщо вершина 1 є стоком, то припишемо їй знак + , а якщо - витоком, то знак - .

Будемо казати, що один такий набір менший за інший, якщо в ньому декілька перших елементів такі самі, як у другого набору, а наступний - менший. Якщо, всі елементи рівні, але знаки при одиниці різні, то найменшим будемо вважати набір зі знаком -.

Кодом потоку будемо називати набір списків зі знаком біля 1 , який є найменшим серед усіх можливих наборів списків, побудованих так, як було описано вище. Приклад коду: $+1-3-5,8-6$.

Теорема 4.1. Два потоки топологічно еквівалентні тоді $i$ тільки тоді, коли у них однакові коди.

Доведення. Необхідність. Оскільки топологічна еквівалентність зберігає порядок вершин і код за сепаратрисною діаграмою виписується однозначно, то з топологічної еквівалентності потоків випливає рівність кодів.

Достатність. 3 рівності кодів випливає, що сепаратрисні діаграми еквівалентні. Еквівалентність задається відображенням, яке переводить вершини однієї діаграми у вершини з тими самими номерами на іншій діаграмі.

\section{5. ПРИКЛАДИ ЗАСТОСУВАНЬ ТА ОБЧИСЛЕНЬ}

Покажемо, як можна застосовувати побудовані вище інваріанти для обчислення кількості топологічно не еквівалентних потоків із заданим числом сепаратрис. 
Якщо у потоку немає сепаратрис, то він має дві особливі точки стік і витік. Всі такі потоки мають таку саму структуру, що і потік, зображений на рис. 5.2.

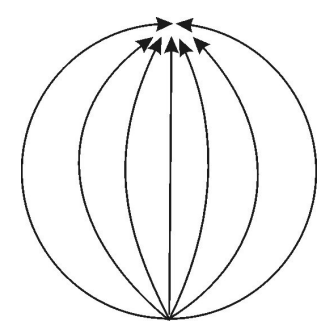

Рис. 5.2. Потоки без сідел

Для потоків з однією сепаратрисою можливі два коди: $-1-3$ (рис. 5.3) та $+1-3$.

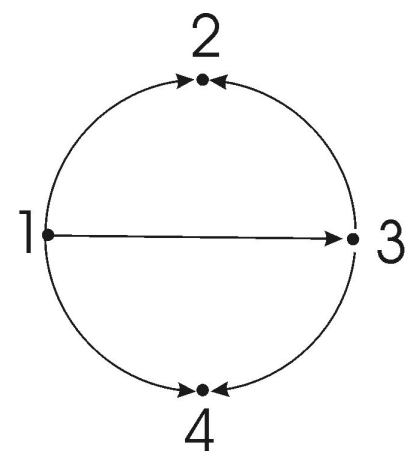

Рис. 5.3. Сепаратрисна діаграма потоку з кодом $-1-3$

Для потоків з двома сепаратрисами можливі чотири коди:
1) $-1-3-5$ (Рис. 5.4 зліва);
3) $-1-3,4-6$;
2) $+1-3-5$;
4) $-1-3,6-4$ (Рис. 5.4 справа).

Перші два коди відрізняються тільки знаком. Тому будемо записувати їх як $\pm 1-3-5$. Третій і четвертий коди відрізняються порядком і ми запишемо їх як $-1-3, \pm 4-6$.

Для потоків з трьома сепаратрисами можливі чотирнадцять кодів:

$$
\begin{array}{llrl}
1,2) & \pm 1-3-5-7 ; & 9-12) & \pm 1-3,4-8, \pm 5-7 \\
3,4) & \pm 1-3-7,4-6 ; & 13-14) & \pm 1-3,7-5,8-4 \\
5-8) & \pm 1-3-5, \pm 4-6 ; & &
\end{array}
$$



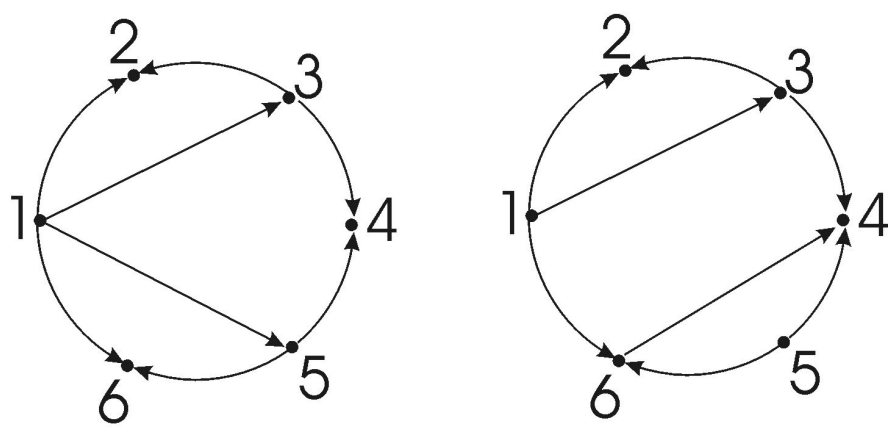

Рис. 5.4. Сепаратрисні діаграми потоків з кодами $-1-$ $3-5$ та $-1-3,6-4$

Провівши аналогічні міркування можна пересвідчитись, що з чотирма сепаратрисами можливі 35 потоків, а 3 п'ятьма сепаратрисами 190 різних потоків.

\section{Висновок}

В роботі розглядалися потоки на двовимірному диску, у яких всі особливі точки є гіперболічними і лежать на межі. Доведено критерій топологічної еквівалентності таких потоків. Отримані в роботі результати повністю вирішують проблему структурної класифікацї̈ оптимальних потоків з гіперболічними особливими точками на межі двовимірного диска. Автори сподіваються, що вдасться отримати аналогічні результати для інших поверхонь з межею.

\section{ЛIтеРАТУРА}

[1] G. Fleitas. Classification of gradient-like flows on dimensions two and three. Bulletin of Brazilian Mathematical Socienty, 6(2):155-183, 1975.

[2] E. Girik. Classification of polar Morse-Smale vector fields on two-dimensional manifolds. Meth. Funct. Anal. Topology, 2(1):23-37, 1996.

[3] R. Labarca and M. J. Pacifico. Stability of Morse-Smale vector fields on manifolds with boundary. Topology, 29(1):57-81, 1990.

[4] J. Palis. On Morse-Smale dynamical systems. Topology, 8:385-405, 1996.

[5] J. Palis and S. Smale. Structural stability theorems. Proc. Sympose. Pure Math., 14:223-231, 1970.

[6] D. Poltavec. Equivalent polar Morse-Smale systems on two-dimensional manifolds of genus 3. In International Conference on Topology and Applications, Book of Abstracts, page 29, 1995. 
[7] C. Robinson. Structural stability on manifolds with boundary. Journal of Differential Equations, 37(1):1-11, 1980.

[8] О. Кадубовський. Класифікація векторних полів Морса- Смейла на двовимірних многовидах. Вісник Київсъкого начіонального університету ім. Тараса Шевченка. Математика, механіка., 14:85-88, 2005.

[9] А. О. Пришляк М. В. Лосева. О структурно устойчивых обыкновенных дифференциальных уравнениях на поверхностях с краем. Журнал обчисл. та приклад. математики, 87(1):45-48, 2002.

[10] О. О. Пришляк М. В. Лосєва. МС-потоки на тривимірних многовидах з краєм. Вісн. КНУ, Mam. Mex., 15:31-32, 2006.

[11] А. О. Пришляк. Топологическая классификация т-полей на двух- и трех-мерных многообразиях с краем. Укр.мат. журн., 55(6):799-805, 2003.

Надійшло до редакиї 11 квітня 2016, прийнято до друку 20 травня 2016.

\author{
Лосєва Марія Вікторівна \\ КНУ Ім. Т.Г. ШЕВченКА, КИїв, УКРАїнА \\ Email: mv.loseva@gmail.com \\ Пришляк Олександр Олегович \\ КНУ Ім. Т.Г. ШЕВчеНКА, КИїв, УкРАїнА \\ Email: prishlyak@yahoo.com \\ ORCID: orcid.org/0000-0002-7164-807X
}

